\title{
Evaluation of Hemostatic Parameters in Tumor-Bearing Dogs
}

\author{
Denner Santos dos Anjos', Juliana Santilli², Aline Fernandes Vital'2, \\ Jéssica Rodrigues de Oliveira', Márcia Ferreira da Rosa Sobreira', Geórgia Modé Magalhãe³, \\ Sabryna Gouveia Calazans ${ }^{1,2}$ \& Carlos Eduardo Fonseca-Alves ${ }^{4}$
}

\begin{abstract}
Background: Hemostatic alterations are commonly detected in canine cancer patients. However, few studies have described hemostatic dysfunction in dogs with different tumor subtypes. In Veterinary Medicine, the state of hypercoagulability is hardly diagnosed alive, since laboratory exams for evaluate hemostatic function are not always requested. Due to importance of homeostatic disorders in cancer patients, this study aimed to evaluate hemostatic alterations such as platelet count, activated partial thromboplastin time (aPTT), prothrombin time (PT) and fibrinogen in tumor-bearing dogs.

Materials, Methods \& Results: From the 55 dogs evaluated, 30 had mammary carcinoma, 6 visceral hemangiosarcoma, 9 high-grade cutaneous mast cell tumor and 10 multicentric lymphoma. The results were compared to a control group composed by 10 Beagle dogs. Thrombocytosis was observed in $26.6 \%$ (8/30) of mammary carcinoma group and thrombocytopenia in 10\% (3/30). The patients with hemangiosarcoma and mast cell tumor did not reveal thrombocytosis, however, thrombocytopenia was present in 16.6\% (1/6) and 33\% (3/9), respectively. Three dogs with multicentric lymphoma showed thrombocytopenia and other three showed thrombocytosis. From patients with thrombocytosis, one was classified as severe thrombocytosis $\left(1077 \times 10^{3} / \mu \mathrm{L}\right)$. Therefore, there were no statistically significant associations between neoplasia group with control group $(P>0.05)$. Regarding the aPTT and PT evaluation, mammary carcinoma $(P=0.0005)$, hemangiosarcoma $(P$ $=0.033)$ and mast cell tumor $(P=0.012)$ patients showed statistical difference for aPTT, while the evaluation for PT was not significant $(P>0.05)$. We grouped all patients as a "tumor group" and compared to the control group. It was possible to observe increased aPTT and PT in 89\% (49/55) and 50.90\% (28/55) respectively, in tumor group compared to normal. A total of $47.27 \%(n=26)$ of the patients with tumors presented increased aPTT and PT concomitantly. In the present study, $14.54 \%$ of the patients presented elevated levels of fibrinogen associated with increased aPTT. However, only the mast cell tumor group was statistically significant $(P=0.043)$.

Discussion: Hemostatic alterations can be found in dogs with cancer and when these alterations occurs, can be directly associated with tumoral non-invasive actions called as paraneoplastic syndrome. However, the hemostatic paraneoplastic syndrome is poorly reported in veterinary medicine, with limited number of papers describing this condition. Our results indicated that the presence of thrombocytosis in patients with tumors could be related with the production of granulocytemacrophage colony stimulating factors (GM-CSF) and IL-6 by tumor cells. A total of 26 patients with tumors presented increased aPTT and PT concomitantly, confirming that hemostatic dysfunction is a common alteration in dogs with neoplasia. However, despite alterations in coagulation parameters, there were no clinical manifestations of bleeding such as petechial or bruising in these patients. The increased fibrinogen and aPTT can be caused by a systemic inflammatory reaction mediated by pro-inflammatory cytokines produced by tumors cells. Based on that, $14.54 \%$ of the animals presented elevated levels of fibrinogen associated with elevated aPTT suggesting that these patients are associated with systemic inflammation and tumor progression. This study suggested that bearing-tumors patients shows important hemostatic dysfunctions, elucidating the clinical importance of these results in veterinary medicine.
\end{abstract}

Keywords: aPPT, dogs, fibrinogen, hemostatic dysfunction, platelets, PT.

${ }^{1}$ Veterinary Teaching Hospital, Department of Veterinary Science, Universidade Estadual Paulista (UNESP), Jaboticabal, SP, Brazil. ${ }^{2}$ Veterinary Teaching Hospital, Department of Veterinary Science, Universidade de Franca (UNIFRAN), Franca, SP. ${ }^{3}$ Instituto Federal de Educação Ciência e Tecnologia do Sul de Minas (IFSM), Muzambinho, MG, Brazil. ${ }^{4}$ Department of Veterinary Clinic, School of Veterinary Medicine and Animal Science, Universidade Estadual Paulista (UNESP), Botucatu, SP. CORRESPONDENCE: D.S. Anjos [dennerbiovet@ hotmail.com - Tel.: +55 (67) 98144-8191]. Departamento de Medicina Veterinária, Universidade Estadual Paulista (UNESP), Câmpus de Jaboticabal. Via de Acesso Prof. Paulo Donato Castellane, s/n. Bairro Vila Industrial. CEP 14884-900 Jaboticabal, SP, Brazil. 


\section{INTRODUCTION}

Hemostatic dysfunction is a common disorder in human patients with neoplasia, who often present clinical signs of venous thromboembolism (VTE), pulmonary thromboembolism (PTE), or disseminated intravascular coagulation (DIC) [4,29]. In dogs, neoplasia has been associated with PTE, although this condition is rarely diagnosed in lifespan $[13,15,16]$. As in human medicine, DIC has been reported in veterinary medicine, such in metastatic mammary carcinoma [20], acute lymphoblastic leukemia [21] and hemangiosarcoma [11].

According to Andreasen et al. [1], subclinical hemostatic alterations associated with neoplasia appear to be common in dogs. One previous study found that $83 \%$ of dogs affected by neoplasia presented alterations in coagulation parameters and $36 \%$ presented thrombocytopenia [19].

Although hypercoagulability and thromboembolism are common in tumor-bearing dogs, hypocoagulability and hemorrhage occur less frequently [5]. Despite the importance of the diagnosis of hemostatic disorders, some of the patients who underwent a tumor surgical resection, although asymptomatic, may have subclinical thromboembolism or DIC and present unexpected complications, including hemorrhage, which can be fatal $[1,5,14]$. Considering the importance and complexity of the hemostatic mechanism in dogs with malignant neoplasia, this study aimed to evaluate the coagulogram by counting platelets, aPTT, PT and fibrinogen in tumor-bearing dogs.

\section{MATERIAL AND METHODS}

\section{Study population}

This was a prospective observational study carried out at the Veterinary Hospital which 55 dogs with a mean age of $9.6( \pm 3.14)$ years were studied, being 44 females and 11 male dogs. The dog breeds were American Pitbull $(n=6)$, Rottweiler $(n=4)$, Boxer dog $(n=3)$, Cocker Spaniel $(n=2)(N=2)$, Bull Terrier ( $\mathrm{n}=2)$, Pinscher $(\mathrm{n}=1)$, Belgian Shepherd ( $\mathrm{n}$ $=1)$, Brazilian terrier $(n=1)$, Dalmatian $\operatorname{dog}(n=1)$, Teckel $(n=1)$, Fox Terrier $(n=1)$ and Border Collie $(n=1)$. As a control group, 10 healthy Beagle adult dogs from were used.

In order to evaluate the influence of each tumor type on hemostatic parameters, the animals were grouped according to tumor histological type: mammary carcinoma $(n=30)$, hemangiosarcoma $(n=6)$, cutaneous mast cell tumor $(\mathrm{n}=9)$ and multicentric lymphoma $(n=10)$. The diagnosis was obtained by histopathological examination. Patients previously treated with non-steroidal anti-inflammatory drugs, corticosteroids or antineoplastic chemotherapy were excluded from this study.

\section{Blood samples}

Blood specimen collection was performed prior to therapeutic or surgical treatment. Total blood was collected from the jugular vein. For hemostatic parameters, the blood was packed in tubes containing sodium citrate at a ratio of 1: 9 , and also in tubes containing EDTA (ethylenediaminetetraacetic acid) intended for platelet counting. Immediately after collection, the samples were centrifuged at $1500 \mathrm{~g}$ for $15 \mathrm{~min}$.

\section{Coagulation tests}

Platelet counts were performed using an automatic cell counter (BC 2800VET, Mindray). To verify the acuity of the counting by the apparatus, blood stains were stained using panoptic ${ }^{1}$ and were analyzed by light microscopy (increase of 100x) by the same observer. The PT, aPPT and the fibrinogen dosage were performed using a coagulometer (COAG 1000) $)^{2}$, using reagents from the same brand of the device, according to the manufacturer's recommendations.

\section{Statistical analysis}

For statistical propose, all hemostatic parameters (tumor groups vs control) were compared with the reference values described by Thrall et al. [37] and were divided into two groups: "normal" when reference value is according with the reference and "altered" when de values are over or down compared to the reference. Then, the platelet, aTTP, PT and fibrinogen results were submitted to contingency analysis by the Fisher exact test between the tumor groups and the control group. For the analysis, the GraphPad Prism ${ }^{\circledR}$ program (version 6.0) was used, with a significance level of $5 \%$.

\section{RESULTS}

The percentage values of each hemostatic parameter of the dogs affected by neoplasms are described in Table 1 . The mammary carcinoma group, 
presented a platelet count mean of $389.43( \pm 149.93)$ x $10^{3} / \mu \mathrm{L}$, with thrombocytosis in $26.6 \%(\mathrm{n}=8)$ of the cases and thrombocytopenia in $10 \%(\mathrm{n}=3)$. In dogs with hemangiosarcoma and cutaneous mast cell tumors, thrombocytosis was not observed, but thrombocytopenia was present in $16.6 \%(\mathrm{n}=1)$ of the dogs with hemangiosarcoma and $33 \%(n=3)$ in dogs with cutaneous mast cell tumor.

Three dogs (3/10) with multicentric lymphoma presented thrombocytopenia and other three (3/10) presented thrombocytosis, one case being considered as severe thrombocytosis $\left(1077 \times 10^{3} / \mu \mathrm{L}\right)$. However, there was no statistical difference between each tumor group when compared to the control group $(P>0.05)$. Dogs with mammary carcinoma $(P=0.0005)$, hemangiosarcoma $(P=0.033)$, and cutaneous mast cell tumor $(P=0.012)$ presented a difference between the means of aPTT, but there was no statistical difference for PT between each tumor group when compared to the control group $(P>0.05)$ [Figures 1 and 2].

There was no statistical difference between the mammary carcinoma, hemangiosarcoma and lymphoma groups when compared to the control group for fibrinogen levels. However, for the cutaneous mast cell tumors group, we found a higher fibrinogen levels in tumor group compared to normal $(P=0.043)$ [Figure 3].

Table 1. Results of haemostatic alterations of 55 dogs bearing tumors.

\begin{tabular}{|c|c|c|c|c|c|c|c|}
\hline \multirow{2}{*}{$\frac{\text { Neoplasias }}{\text { Mammary carcinoma }(\mathrm{n}=30)}$} & \multirow{2}{*}{ Parameters* } & \multicolumn{2}{|c|}{$\%$ normal range } & \multicolumn{2}{|c|}{$\%$ below } & \multicolumn{2}{|c|}{$\%$ above } \\
\hline & & $\mathrm{N}$ & $\%$ & $\mathrm{~N}$ & $\%$ & $\mathrm{~N}$ & $\%$ \\
\hline Platelet count $\left(\mathrm{x} 10^{3} / \mu \mathrm{L}\right)$ & $200-500$ & 19 & 63.3 & 3 & 10 & 8 & 26.6 \\
\hline aPTT (s) & $9-11$ & 1 & 3.5 & 1 & 3.5 & 26 & 92.85 \\
\hline PT (s) & $6.4-7.4$ & 6 & 22.2 & 5 & 18.5 & 16 & 59.25 \\
\hline Fibrinogen (mg/dL) & $100-500$ & 16 & 57.14 & 9 & 32.14 & 3 & 10.71 \\
\hline \multicolumn{8}{|l|}{ Hemangiosarcoma $(\mathrm{n}=6)$} \\
\hline Platelet count $\left(\mathrm{x} 10^{3} / \mu \mathrm{L}\right)$ & $200-500$ & 5 & 83.3 & 1 & 16.6 & 0 & 0 \\
\hline aPTT (s) & $9-11$ & 0 & 0 & 0 & 0 & 6 & 100 \\
\hline PT (s) & $6.4-7.4$ & 1 & 16.6 & 3 & 50 & 2 & 33.3 \\
\hline Fibrinogen $(\mathrm{mg} / \mathrm{dL})$ & $100-500$ & 4 & 66.6 & 1 & 16.6 & 1 & 16.6 \\
\hline \multicolumn{8}{|l|}{ Mast cell tumor $(\mathrm{n}=9)$} \\
\hline Platelet count $\left(\mathrm{x} 10^{3} / \mu \mathrm{L}\right)$ & $200-500$ & 6 & 66.6 & 3 & 33.3 & 0 & 0 \\
\hline aPTT (s) & $9-11$ & 0 & 0 & 0 & 0 & 8 & 100 \\
\hline PT (s) & $6.4-7.4$ & 1 & 12.5 & 2 & 25 & 5 & 62.5 \\
\hline Fibrinogen $(\mathrm{mg} / \mathrm{dL})$ & $100-500$ & 3 & 37.5 & 3 & 37.5 & 2 & 25 \\
\hline \multicolumn{8}{|l|}{ Lymphoma $(\mathrm{n}=10)$} \\
\hline Platelet count $\left(\times 10^{3} / \mu \mathrm{L}\right)$ & $200-500$ & 4 & 40 & 3 & 30 & 3 & 30 \\
\hline aPTT (s) & $9-11$ & 1 & 10 & 0 & 0 & 9 & 90 \\
\hline PT (s) & $6.4-7.4$ & 3 & 30 & 2 & 20 & 5 & 50 \\
\hline Fibrinogen (mg/dL) & $100-500$ & 5 & 50 & 3 & 30 & 2 & 20 \\
\hline
\end{tabular}

aPTT: activated partial thromboplastin; PT: prothrombin time. *Baker DC. Diagnosis of disorders of hemostasis. In: Veterinary hematology and clinical chemistry. [2]. 


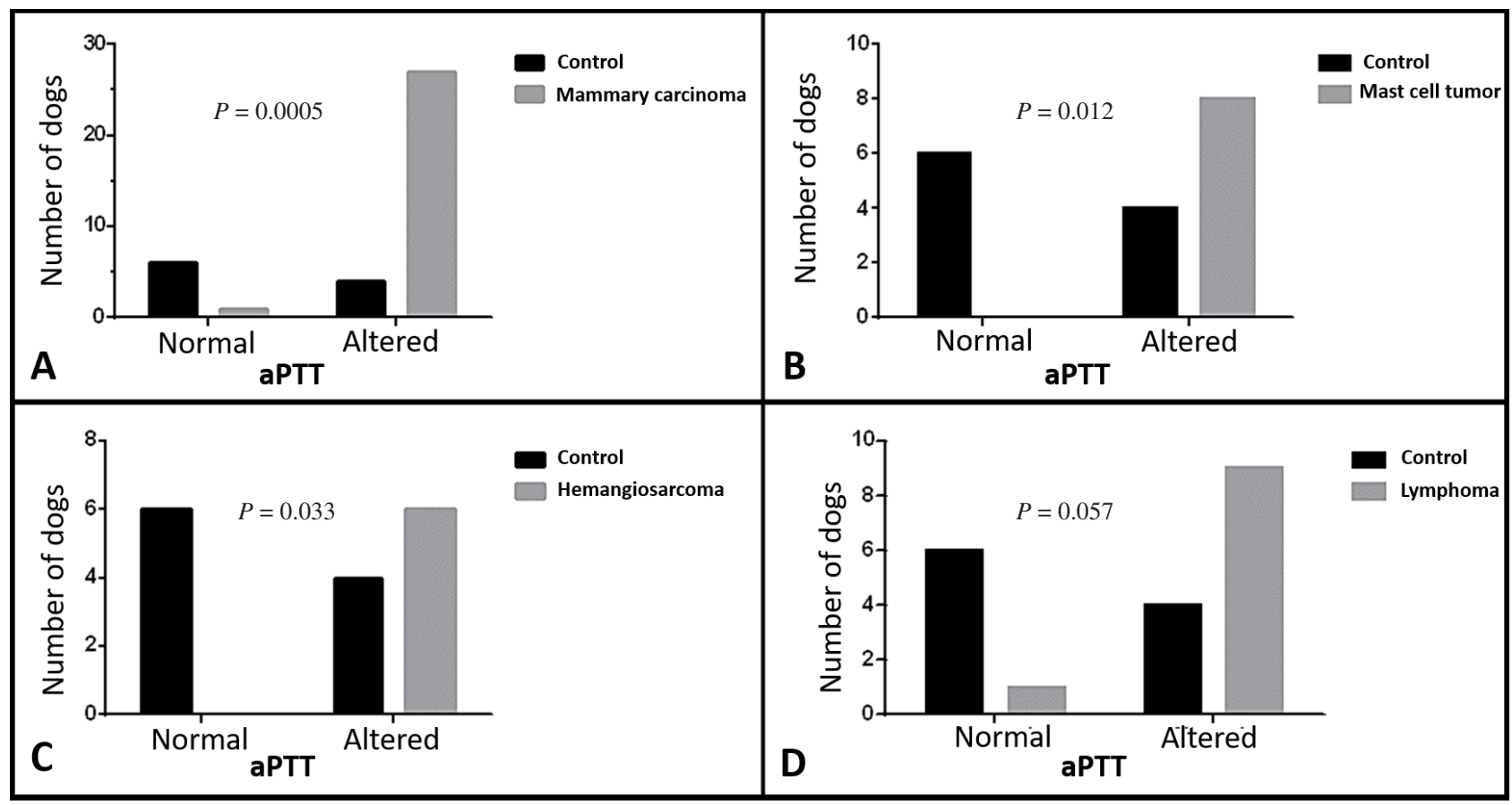

Figure 1. Graphical representation of activated partial thromboplastin (aPTT) in dogs with different tumors. A- There is a significant difference of aPTT between the control group and mammary carcinoma $(P=0.0005)$. B- Significant alteration of aPTT between the control and mast cell tumor groups $(P$ $=0.012)$. $\mathrm{C}$ - Significant alteration in aPTT between the hemangiosarcoma and control group $(P=0.023)$. D- There was no significant difference between the control and lymphoma groups $(P=0.057)$.

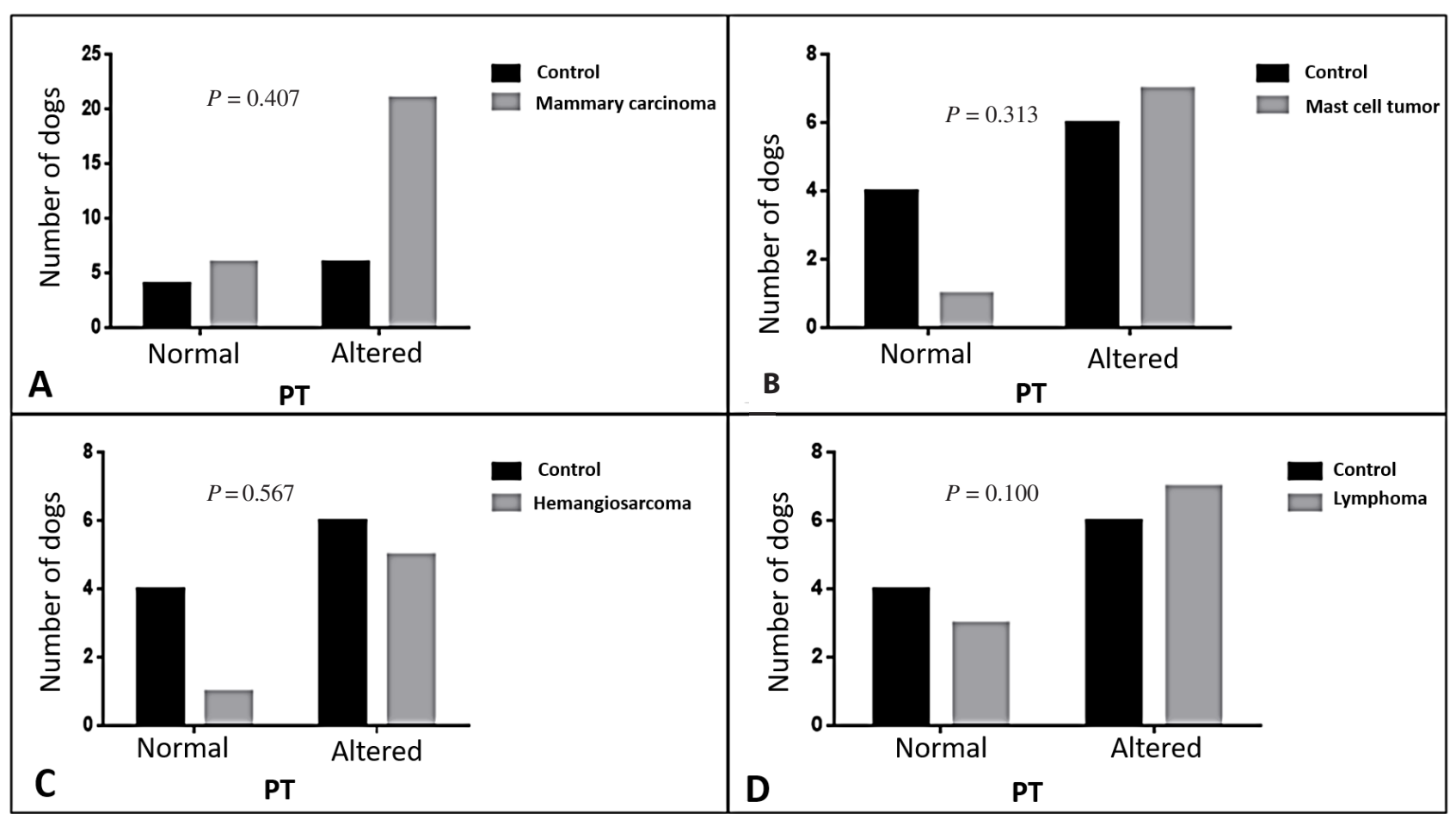

Figure 2. Graphical representation of prothrombin time (PT) in dogs with different tumors. There was no significant difference between the different tumors group and control $(P>0.05)$. 


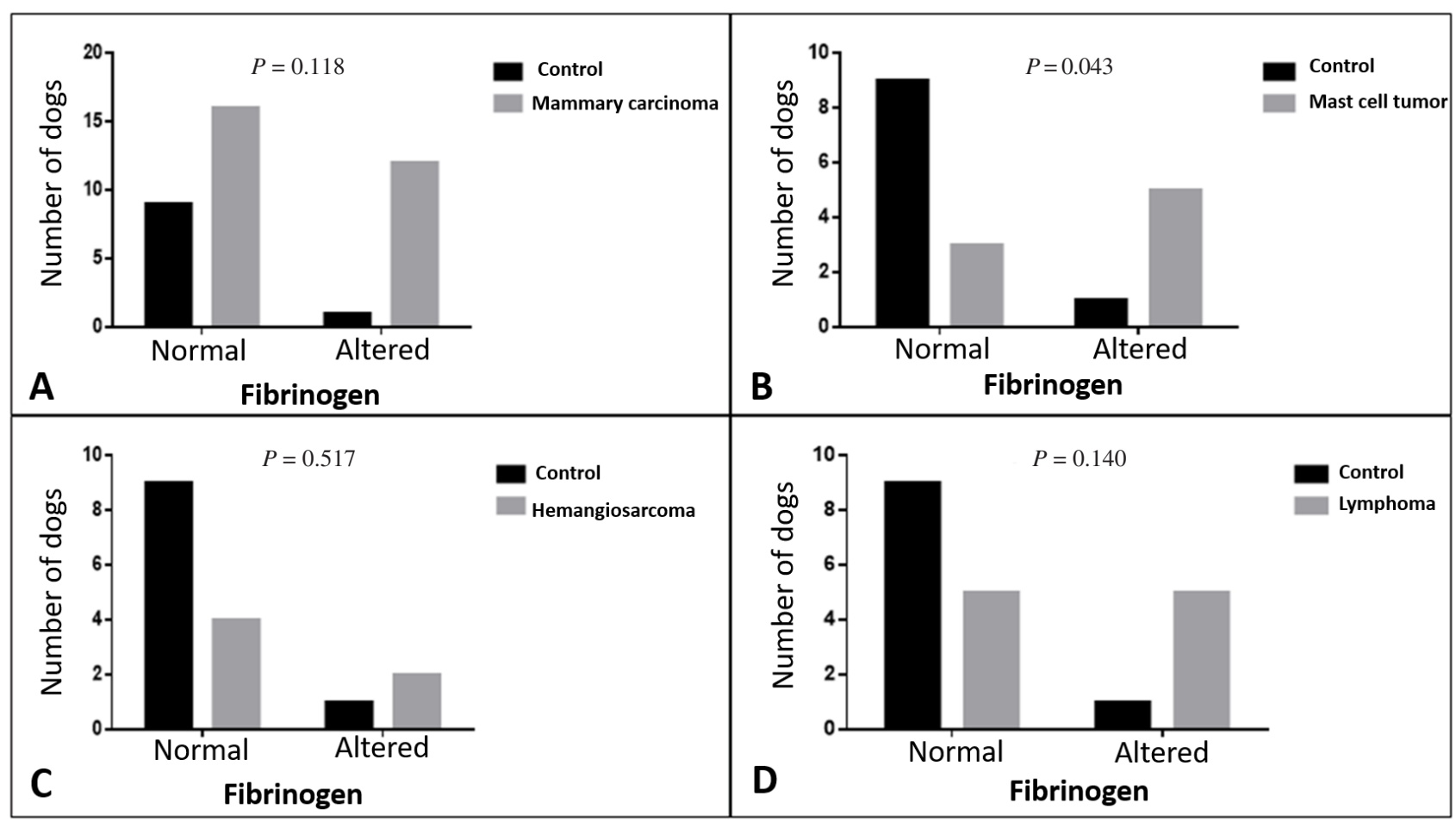

Figure 3. Graphical representation of fibrinogen in dogs with different tumors. There is no significant difference in fibrinogen in the mammary carcinoma, hemangiosarcoma and lymphoma groups compared to control group (A, C, D). There is a significant alteration in fibrinogen in mast cell tumor group compared to control $[P=0.043]$ (B).

\section{DISCUSSION}

Hemostatic alterations can be found in dogs with cancer and when these alterations is directly associated with tumor non-invasive actions is called as paraneoplastic syndrome. Human patients affected by different tumors subtypes can show $58-98 \%$ of hemostatic alteration evidenced in laboratory tests [8]. The hemostatic paraneoplastic syndrome is well documented in human medicine, however, in Veterinary Medicine; there is a limited number of papers describing this condition. According to the previous literature $[18,23]$, thrombocytosis is commonly associated with neoplastic processes. However, a very accurate approach need to be performed to associate the hemostatic alteration as a tumor non-invasive action. Our results indicated presence of thrombocytosis in $20 \%(11 / 55)$ of the subjects with neoplasia. This result was higher than the previously reported incidence of $4.5 \%$ and $8.5 \%[11,23]$. Studies in humans have shown that carcinoma-associated thrombocytosis may be related to the tumor production of granulocytemacrophage colony stimulating factors (GM-CSF) and IL-6 [3,36]. Our research group previously reported a paraneoplastic leukocytosis in a cat with mammary gland carcinoma expressing GM-CSF [12].
On the other hand, a study evaluated 2,059 dogs with different tumors subtypes and detected thrombocytopenia in only $10 \%$ of the animals, most frequently observed in cases of lymphoid neoplasms, carcinomas and sarcomas [10]. Other study has shown that hypercoagulability, thrombocytosis and increased fibrinogen were the most common findings in dogs with carcinoma when compared to healthy dogs [30].

The previous literature has been reporting a platelet interaction with tumor cells to promote metastasis. Thus, correlating thrombocytosis with poor prognosis in human patients with various neoplasms such as colon, breast, lung, gastric, brain and ovarian tumors $[9,34,39]$.

It was possible to observe augmentation of aPTT and PT in $89 \%$ (49/55) and 50.90\% (28/55) respectively, in tumor group compared to normal. A total of $47.27 \%$ $(n=26)$ of the dogs with neoplasms presented increased aPTT and PT concomitantly, confirming that hemostatic dysfunction is a common alteration in dogs with neoplasia, as other studies have reported [1,32]. However, despite changes in coagulation parameters, there were no clinical manifestations of bleeding such as petechial or bruising in these patients. Similar results were observed by Stockhaus et al. [32] that despite the high incidence of changes in 
coagulation parameters, the clinical manifestation of bleeding was not observed frequently. The incidence of hemostatic dysfunction (increased aPTT and PT) in female dogs with mammary carcinoma [32] was similar to our results.

The state of hypocoagulability has traditionally been characterized by the increase of aPTT, observed between $4.2-17 \%$ of dogs with malignant neoplasms such as mammary carcinoma and lymphoma $[1,14,32]$. We also observed the increase of aPTT in $89 \%$ (49/55) of dogs with malignant tumors, suggesting a state of hypocoagulability. However, Kristensen et al. [14], when performing TEG in dogs with increased aPTT, surprisingly resulted in hypercoagulability, indicating that when evaluated in isolation of hemostatic system components, aPTT or other traditional coagulation assays may erroneously indicate hypocoagulability. Therefore, TEG is the most appropriate test to evaluate the true state of hypocoagulability, since it involves the interaction of all hemostasis cells and proteins, but future prospective studies including a large number of animals with hypocoagulability and correlation of the results with the TEG allied to the clinical signs of bleeding are necessary.

The mean values of fibrinogen observed in the mast cell tumor and control groups corresponded respectively to $249 \mathrm{mg} / \mathrm{dL}( \pm 211)$ and $240 \mathrm{mg} / \mathrm{dL}$ ( \pm 26.13). It is known that fibrinogen is an essential hemostatic factor presenting important function in the coagulation system and tumor angiogenesis [31], and its alteration is associated with tumor progression, metastasis and survival in human patients [26-28,35]. It is reported that the increase of fibrinogen combined with other hemostatic alterations such as augmentation of the aPTT is a result of a systemic inflammatory reaction mediated by pro-inflammatory and tumor processes $[6,17,38]$. In the present study, $14.54 \%$ of the animals presented elevated levels of fibrinogen associated with elevated aPTT, corroborating the previously mentioned studies, suggesting that these patients are associated with systemic inflammation and tumor progression. This fact has been observed in other studies, evidencing hyperfibrinogenemia in female dogs with mammary carcinoma at an advanced stage of the disease [1,32]. Another study observed an increase in fibrinogen levels in $87 \%$ of dogs with carcinoma, lymphoma and sarcoma [24], higher values of the present study. The results of this research indicate that the patients with malignant tumors present important hemostatic alterations. Thus, it is suggested that all cancer patients should be submitted to evaluation of hemostasis, since many patients may present a subclinical DIC stage without evident clinical signs of thromboembolism and / or hemorrhage.

\section{MANUFACTURERS}

${ }^{1}$ Laborclin Produtos Ltda. Pinhais, PR, Brazil.

${ }^{2}$ Wama Diagnóstica. São Carlos, SP, Brazil.

Funding. This research was supported by the São Paulo Research Foundation (FAPESP 2012/23654-3).

Ethical approval. This study was performed according to Brazilian Council for Animal Care and approved by the 'Ethics Committee in the Use of Animals' of the Veterinary Teaching Hospital at the University of Franca - UNIFRAN (Protocol number 001/2013). All animal owners gave written informed consent for the dog's material, clinical information and examination results to be used for research and academic matters.

Declaration of interest. The authors report no conflicts of interest. The authors alone are responsible for the content and writing of the paper.

\section{REFERENCES}

1 Andreasen E.B., Tranholm M., Wiinberg B., Markussen B. \& Kristensen A. 2012. Haemostatic alterations in a group of canine cancer patients are associated with cancer type and disease progression. Acta Veterinaria Scandinavica. 54: 3.

2 Baker D.C. 2012. Diagnosis of disorders of hemostasis. In: Thrall M.A., Weiser G., Allison R.W. \& Campbell T.W. (Eds). Veterinary Hematology and Clinical Chemistry. 2nd edn. Ames: Wiley-Blackwell, John Wiley \& Sons Company, p.202.

3 Benoy I., Salgado R., Colpaert C., Weytjens R., Vermeulen P.B. \& Dirix L.Y. 2002. Serum interleukin 6, plasma VEGF, serum VEGF, and VEGF platelet load in breast cancer patients. Clinical Breast Cancer. 2: 311-315.

4 Buller H.R., van Doormaal F.F., van Sluis G.L. \& Kamphuisen P.W. 2007. Cancer and thrombosis: from molecular mechanisms to clinical presentations. Journal of Thrombosis Haemostasis. 5: 246-254.

5 Childress M.O. 2012. Hematologic Abnormalities in the Small Animal Cancer Patient. Veterinary Clinics North American Small Animal Practice. 42: 123-155. 
6 Eckersall P.D. \& Conner J.G. 1988. Bovine and canine acute phase proteins. Veterinary Research Communications. 12: 169-178.

7 Edwards R.L., Rickles F.R., Moritz T.E., Henderson W.G., Zacharski L.R., Forman W.B., Cornell C.J., Forcier R.J., O'Donnell J.F. \& Headley E. 1987. Abnormalities of blood coagulation tests in patients with cancer. American Journal Clinical Pathology. 88: 596-602.

8 Francis J.L., Biggerstaff J. \& Amirkhosravi A. 1998. Hemostasis and malignancy. Seminars Thrombosis Hemostasis. 24: 93-109.

9 Gay L.J. \& Felding-Habermann B. 2011. Contribution of platelets to tumor metastasis. Nature Reviews Cancer. 11: 123-134.

10 Grindem C.B., Breitschwerdt E.B., Corbett W.T., Page R.L. \& Jans H.E. 1994. Thrombocytopenia associated with neoplasia in dogs. Journal of Veterinary Internal Medicine. 8: 400-405.

11 Hammer A.S., Couto C.G., Swardson C. \& Getzy D. 1991. Hemostatic abnormalities in dogs with hemangiosarcoma. Journal of Veterinary Internal Medicine. 5: 11-14.

12 Jark P.C., Raposo-Ferreira T.M., Terra E.M., Sierra Matiz O.R., Anai L.A., Fonseca-Alves C.E., Tinucci-Costa M., Laufer-Amorim R. \& De Nardi A.B. 2015. Paraneoplastic neutrophilic leukocytosis syndrome in a cat with recurrent mammary carcinoma. Journal of Feline Medicine and Surgery Open Reports. 12: 1-2.

13 Johnson L.R., Lappin M.R. \& Baker D.C. 1999. Pulmonary thromboembolism in 29 dogs: 1985-1995. Journal of Veterinary Internal Medicine. 13: 338-345.

14 Kristensen A.T., Wiinberg B., Jessen L.R., Andreasen E. \& Jensen A.L. 2008. Evaluation of human recombinant tissue factor-activated thromboelastography in $49 \mathrm{dogs}$ with neoplasia. Journal of Veterinary Internal Medicine. 22: 140-147.

15 LaRue M.J. \& Murtaugh R.J. 1990. Pulmonary thromboembolism in dogs: 47 cases (1986-1987). Journal of American Veterinary Medical Association. 197: 1368-1372.

16 Laurenson M.P., Hopper K., Herrera M.A. \& Johnson E.G. 2010. Concurrent diseases and conditions in dogs with splenic vein thrombosis. Journal of Veterinary Internal Medicine. 24: 1298-1304.

17 Levi M. \& van der Poll T. 2005. Two-way interactions between inflammation and coagulation. Trends Cardiovascular Medicine. 15: 254-259.

18 Lubas C., Caldin M., Wiinberg B. \& Kristensen A.T. 2010. Laboratory testing of coagulation disorders. In: Weiss D.J. \& Wardrop K.L. (Eds). Schalm's Veterinary Hematology. 6th edn. Ames: Wiley-Blackwell, John Wiley \& Sons Company, pp.1082-1100.

19 Madewall B.R., Feldman B.F. \& O’Neill S. 1980. Coagulation abnormalities in dogs with neoplastic disease. Thrombosis Haemostasis. 44: 35-38.

20 Mischke R., Wohlsein P., Busse L. \& Pohlenz J. 1998. Disseminated intravascular coagulation and hyperfibrinolysis in dogs with metastasizing mammary carcinoma. Schweiz Archiv Tierheilkunde. 140: 497-505.

21 Mischke R., Freund M., Leinemann-Fink T., Eisenberger B., Casper J. \& Nolte I. 1998. Changes in hemostasis of dogs with acute lymphoblastic leukemia. Berliner Munchener Tierarztliche Wochenschrift. 111: 53-59.

22 Nelson O.L. \& Andreasen C. 2003. The utility of plasma D-dimer to identify thromboembolic disease in dogs. Journal of Veterinary Internal Medicine. 17: 830-834.

23 Neel J.A., Snyder L. \& Grindem C.B. 2012. Thrombocytosis: a retrospective study of 165 dogs. Veterinary Clinical Pathology. 41: 216-222.

24 O'Donnell M.R., Slichter S.J., Weiden P.L. \& Storb R. 1981. Platelet and fibrinogen kinetics in canine tumors. Cancer Research. 41: 1379-83.

25 O'Keefe D.A. \& Couto C.G. 1988. Coagulation abnormalities associated with neoplasia. Veterinary Clinics North America Small Animal Practice. 18: 157-168.

26 Palumbo J.S., Talmage K.E., Liu H., La Jeunesse C.M., Witte D.P. \& Degen J.L. 2003. Plasminogen supports tumor growth through a fibrinogen-dependent mechanism linked to vascular patency. Blood. 102: 2819-2827.

27 Palumbo J.S., Talmage K.E., Massari J.V., La Jeunesse C.M., Flick M.J., Kombrinck K.W., Jirousková M. \& Degen J.L. 2005. Platelets and fibrinogen increase metastatic potential by impeding natural killer cell-mediated elimination of tumor cells. Blood. 105: 178-185. 
28 Perisanidis C., Psyrri A., Cohen E.E., Engelmann J., Heinze G., Perisanidis B., Stift A., Filipits M., Kornek G. \& Nkenke E. 2015. Prognostic role of pretreatment plasma fibrinogen in patients with solid tumors: A systematic review and meta-analysis. Cancer Treatment Review. 41: 960-970.

29 Rickles F.R., Levine M. \& Edwards R.L. 1992. Hemostatic alterations in cancer patients. Cancer Metastasis Reviews. 11: 237-248.

30 Saavedra P.V., Lara García A., Zaldívar López S. \& Couto G. 2011. Hemostatic abnormalities in dogs with carcinoma: a thromboelastographic characterization of hypercoagulability. Veterinary Journal. 190: e78-83.

31 Staton C.A., Brown N.J. \& Lewis C.E. 2003. The role of fibrinogen and related fragments in tumour angiogenesis and metastasis. Expert Opinion Biological Therapy. 3: 1105-1120.

32 Stockhaus C., Kohn B., Rudolph R., Brunnberg L. \& Giger U. 1999. Correlation of haemostatic abnormalities with tumour stage and characteristics in dogs with mammary carcinoma. Journal of Small Animal Practice. 40: 326-331.

33 Stokol T., Brooks M.B., Erb H.N. \& Mauldin G.E. 2000. D-dimer concentrations in healthy dogs and dogs with disseminated intravascular coagulation. American Journal of Veterinary Research. 61: 393-398.

34 Stravodimou A. \& Voutsadakis I.A. 2013. Pretreatment thrombocytosis as a prognostic factor in metastatic breast cancer. International Journal Breast Cancer. 2013: 289563.

35 Sun Z.Q., Han X.N., Wang H.J., Tang Y., Zhao Z.L., Qu Y.L., Xu R.W., Liu Y.Y. \& Yu X.B. 2014. Prognostic significance of preoperative fibrinogen in patients with colon cancer. World Journal Gastroenterology. 20: 8583-8591.

36 Suzuki A., Takahashi T., Nakamura K., Tsuyuoka R., Okuno Y., Enomoto T., Fukumoto M. \& Imura H. 1992. Thrombocytosis in patients with tumors producing colony-stimulating factor. Blood. 80: 2052-2059.

37 Winter P.C. 2006. The pathogenesis of venous thromboembolism in cancer: emerging links with tumour biology. Hematology Oncology. 24: 126-133.

38 Zhang X. \& Ran Y. 2015. Prognostic role of elevated platelet count in patients with lung cancer: a systematic review and meta-analysis. International Journal Clinical and Experimental Medicine. 8: 5379-5387. 